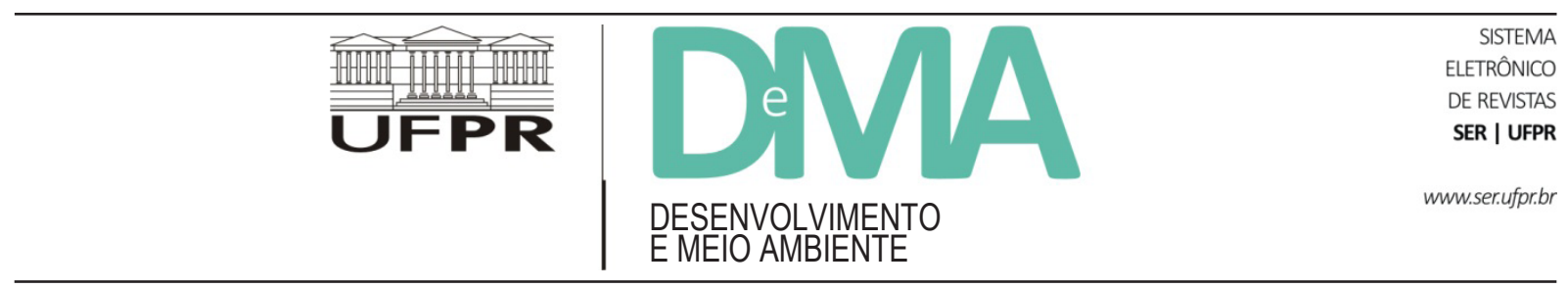

\title{
O "Modelo Broa" e a produção de conhecimento científico sobre o meio ambiente
}

\section{The "Broa Model" and the Productions of Scientific Knowledge on the Environment}

\author{
Raiza CAMPREGHER ${ }^{1 *}$, Rodrigo Constante MARTINS ${ }^{1}$ \\ ${ }^{1}$ Programa de Pós-Graduação em Sociologia, Universidade Federal de São Carlos (UFSCar), São Carlos, SP, Brasil. \\ *E-mail de contato: raiza.campregher@gmail.com
}

Artigo recebido em 11 de novembro de 2016, versão final aceita em 30 de março de 2017.

RESUMO: Partindo da posição destacada do conhecimento científico no trato da questão ambiental na contemporaneidade, o artigo analisa o processo de produção de conhecimento científico sobre a Represa do Broa (SP), tanto por meio da análise da estrutura objetiva do campo científico como das narrativas dos cientistas sobre a pesquisa. A Represa do Broa é possivelmente o reservatório mais estudado no país, muito em função do aparato de produção científica que se formou a seu respeito desde a década de 1970, fundado em um projeto estratégico de desenvolvimento de duas universidades públicas (USP e UFSCar). Os procedimentos metodológicos deste estudo de caso foram a pesquisa documental dos trabalhos científicos produzidos sobre a represa e a realização de entrevistas qualitativas semiestruturadas com pesquisadores do Broa, selecionados de forma proposital.

Palavras-chave: sociedade e meio ambiente; conhecimento científico; Represa do Broa.

ABSTRACT: Starting from the outstanding position of scientific knowledge in dealing with the environmental issue on contemporary times, this paper analyses the process of scientific knowledge production regarding the Broa Dam located in Sao Paulo, both by analyzing the objective structure of the scientific field and through the research narratives of the scientists. The Broa Dam is possibly the most studied reservoir in Brazil, especially because of the scientific production apparatus created in the 1970s, founded in a strategic development project by two public universities (USP and UFSCar). The methodological proceedings of this case study were the documental research of scientific papers on the reservoir, and semi-structured qualitative interviews with Broa researchers, selected on purpose.

Keywords: society and environment; scientific knowledge; Broa Dam. 


\section{Introdução}

Entre as abordagens dominantes na literatura socioambiental, há uma convergência que aponta para o papel destacado do conhecimento científico no trato das questões relativas à natureza. Hannigan (2009) afirma ser quase impossível a construção bem-sucedida de um problema ambiental sem o suporte do estatuto da ciência; Beck (2011) e Giddens (2010) relacionam os efeitos da produção científica ao meio ambiente no contexto da modernidade tardia ou radicalizada; Martínez Alier (2012) propõe uma orquestração de ciências para a superação da moderna crise ambiental. Apenas nesse breve apanhado de autores, é possível visualizar o status do conhecimento científico frente à questão ambiental na contemporaneidade.

É a partir dessa observação que o artigo em tela objetiva analisar o processo de produção de conhecimento científico sobre o meio ambiente, tanto a partir de sua estrutura objetiva de campo como a partir das narrativas dos cientistas sobre a pesquisa. Para tal empreitada, realizamos um estudo de caso na Represa do Broa - situada no interior do Estado de São Paulo -, destacadamente um dos reservatórios mais estudados no país, ${ }^{1}$ muito em função do aparato de produção científica que se formou a seu respeito desde a década de 1970. Os procedimentos metodológicos deste estudo foram a pesquisa documental dos trabalhos científicos produzidos sobre a represa e a realização de entrevistas qualitativas semiestruturadas com pesquisadores do Broa, selecionados de forma proposital.
Em termos teóricos, estamos fundamentados na noção de campo científico (Bourdieu, 2004; 2008) como um universo intermediário, relativamente autônomo, dotado de uma estrutura de relações específicas, em função da distribuição desigual de capitais simbólicos e de sua illusio própria. As relações sociais e as relações sociedade-ambiente no espaço do Broa, dessa forma, podem ser mais bem compreendidas por meio desse conceito se considerarmos a sólida atuação de instituições de pesquisa científica e seus agentes, produzindo um volumoso corpo de textos e de conhecimentos sobre o ambiente do reservatório. Mais precisamente, o campo científico possui duas acepções: ele é, ao mesmo tempo, campo de forças, dotado de uma estrutura de relações objetivas, e campo de lutas, enquanto espaço de conflitos pela manutenção ou transformação desse campo de forças. Nesse sentido, as estratégias abertas aos agentes no campo científico dependem tanto da estrutura do campo como também da mediação do habitus ${ }^{2}$ (Bourdieu, 2008).

A Represa do Lobo, também conhecida como Broa, foi construída em 1936, com o propósito de funcionar como reservatório da Usina Hidrelétrica Carlos Botelho. A represa faz parte da Sub-Bacia Hidrográfica do Rio Itaqueri, cujo principal curso d'água é o Rio Itaqueri, além dos tributários: Ribeirão do Lobo, Córrego Perdizes e Córrego do Geraldo. Contudo, hoje ela é utilizada primordialmente de duas outras formas, para além da produção de energia: como praia de água doce para moradores e turistas da região e como laboratório a céu aberto,

\footnotetext{
${ }^{1}$ O Broa é possivelmente a represa mais estuda no país e está entre as mais estudadas no mundo, sendo objeto de pesquisa de grupos com destacada circulação internacional (Iucif, 2011; SHS, 2013; Campregher, 2016). A proeminência da pesquisa no Broa também foi frequentemente citada pelos cientistas entrevistados por nós.

${ }^{2}$ Em síntese, o conceito de habitus científico, na sociologia bourdieusiana, refere-se a disposições adquiridas, maneiras de ser duráveis que orientam a prática do agente social no campo científico (Bourdieu, 2004).
} 
sobretudo para os pesquisadores dos Programas de Pós-Graduação em Ecologia e Recursos Naturais (UFSCar) e em Ciências da Engenharia Ambiental (USP).

Destarte, a década de 1970 foi um marco nas transformações dos usos sociais da Represa do Broa. Segundo Queiroz (2000), a construção de grandes complexos hidrelétricos supriu em boa medida a necessidade energética de várias regiões do país, de forma que pequenos reservatórios, como a Represa do Broa, deixaram de ter como função principal a geração de energia hidrelétrica. A partir desse momento, a recreação e o turismo surgiram como alternativas de desenvolvimento para esses espaços, quando se iniciaram os primeiros loteamentos de casas de veraneio no Broa. Esse processo, no entanto, ocorreu de maneira lenta e sem planejamento, com pouca interferência do poder público, esboçando-se também uma forte segregação socioespacial. Esse fenômeno fica evidenciado hoje na distribuição dos diferentes locais no entorno da represa, destacando-se: (1) o Balneário Santo Antônio, um loteamento pertencente ao Município de Itirapina, com pequena praia de água doce, muito procurada por turistas, oferecendo as atividades de pesca, passeios de barco, churrasco e camping; (2) a Vila Pinhal, um condomínio fechado de alto padrão junto ao qual se localiza o Broa Golf Resort, oferecendo serviços de hotelaria, recreação e gastronomia, além de campo de golfe, hípica e aviação.

Em paralelo, os anos 1970 também foram o momento de criação do aparato de produção de conhecimento científico sobre a Represa do Broa, a partir de um projeto estratégico de desenvolvimento de duas universidades públicas - USP e UFSCar-, como discutiremos adiante.

\section{O projeto estratégico de pesquisas no Broa}

As pesquisas no Broa tiveram início a partir de um projeto conjunto entre USP e UFSCar na década de 1970, segundo o pesquisador A. ${ }^{3}$ Este é certamente o mais importante pesquisador do espaço do reservatório. ${ }^{4}$ Doutor em Ciências Biológicas (1969) e livre docente em ecologia (1977), ambos pela USP, foi docente do Departamento de Ciências Biológicas da UFSCar e do Departamento de Hidráulica e Saneamento da USP. Nesse período, participou da fundação dos Programas de Pós-Graduação em Ecologia e Recursos Naturais (UFSCar) e em Ciências da Engenharia Ambiental (USP). Atualmente, o pesquisador A está ligado ao Instituto Internacional de Ecologia (IIE), empresa voltada à prestação de serviços na área de gerenciamento de recursos hídricos (IIE, s.d.).

O projeto conjunto, referido pelo pesquisador A, tem um caráter estratégico para as universidades, tanto em relação ao desenvolvimento de um novo campo de pesquisa - a ecologia, que vinha se inserindo nacionalmente naquele período - como para o fortalecimento da relação ensino/pesquisa nas instituições públicas de educação superior. $\mathrm{O}$ Broa foi escolhido, então, para servir como um laboratório de ecologia "ao ar livre", devido à proximidade com a cidade de São Carlos (onde se localizam as duas universidades em questão) e também ao relativo isolamento da bacia hidrográfica da intervenção humana.

\footnotetext{
${ }^{3}$ Optamos por omitir os nomes dos pesquisadores entrevistados por nós, identificando-os apenas por letras, para fins explicativos. Mantivemos as referências nas citações das obras publicadas por pesquisadores do Broa.

${ }^{4} \mathrm{O}$ pesquisador A orientou 25 trabalhos sobre a Represa do Broa até o ano de 2014, além de sua própria tese de livre docência. Esses números representam $22 \%$ do total de 116 trabalhos sobre o reservatório, levantados em pesquisa documental (Campregher, 2016).
} 
Quando eu cheguei na Federal ${ }^{5}$ em 1971, a Federal me contratou para fazer um projeto de ecologia. E a ideia era um trabalho conjunto entre a Federal e a USP no Broa. O Broa naquele tempo não tinha ninguém, não tinha uma residência, era cerrado, não havia nada e era usado muito pouco para recreação. (Pesquisador A, entrevista, 2015)

O pesquisador A também sinaliza em direção ao crescimento da ecologia no campo científico nos anos 1970, inclusive apontando que o estudo da Represa do Broa a partir de uma perspectiva sistêmica, própria da ecologia, constituía uma estratégia fundamental de desenvolvimento institucional para as universidades.

Quando nós começamos a trabalhar, eu pensei em montar um projeto estratégico, porque naquele tempo tinha alguns projetos de reservatórios no Brasil, mas um pouco dirigidos para a engenharia e para a parte sanitária, de biologia sanitária. Mas eu falei “ecologia não tem, tem pouco ou quase nada". Tinha muito pouca coisa, então vou montar um projeto que vai envolver o reservatório, a bacia hidrográfica, mas que será um projeto de longo prazo, estratégico, que sobre esse projeto de pesquisa eu queria colocar a graduação e a pós-graduação. [...] Foi feito um projeto de estudar o reservatório como um todo, como um sistema. Isso foi outra abordagem interessante, porque naquele tempo essa visão sistêmica era muito primitiva no Brasil. Você tinha gente que estudava peixe, que estudava fitoplancton, que estudava zooplancton, os hidrologistas estudavam hidrologia, mas não era uma abordagem geral, não era uma abordagem sistêmica, uma visão de sistema. Esse eu acho que foi um ponto importante do projeto, encarar o reservatório como um sistema. (Pesquisador A, entrevista, 2015)

Assim, a fala do Pesquisador A aponta que as pesquisas na Represa do Broa nascem de forma planejada, com um intuito estratégico para o desenvolvimento de objetivos específicos da produção acadêmica do país. O primeiro objetivo refere-se ao desenvolvimento e fortalecimento da perspectiva sistêmica da ecologia. O segundo objetivo seria o desenvolvimento de uma metodologia de trabalho e tecnologia para o estudo de reservatórios: "E ao mesmo tempo nossa proposta foi desenvolver uma metodologia de trabalho, que também não havia uma sistemática de trabalho e uma tecnologia sobre o estudo de represa" (Pesquisador A, entrevista, 2015). Um terceiro objetivo estratégico, citado pelo Pesquisador $\mathrm{A}$, diz respeito à formação de recursos humanos na área de ecologia e recursos hídricos.

Depois, o terceiro ponto era a formação de recursos humanos. [...] Porque um dos defeitos que existiam no Brasil na época, era que estava se iniciando os programas de pós-graduação, é que havia um afastamento entre o projeto do curso e o projeto de pesquisa. As vezes o curso não era muito bem embasado na pesquisa. Nem a graduação. [...] Então, nós imediatamente fizemos o projeto, nós começamos a treinar estagiários lá na Represa do Lobo, os estudantes de Biologia de graduação, nós pegamos cinco estagiários inicialmente. Uma delas que vai confirmar isso para você, a professora [Pesquisadora $\mathrm{F}]^{6}$, que hoje é titular, mas começou como estagiária do projeto. E, portanto, a ideia era sempre colocar junto com o desenvolvimento científico um projeto de capacitação, que no início começou com a iniciação científica e depois foi evoluindo, porque mais tarde a proposta foi fazer um mestrado e doutorado sobre esse projeto. Que geraram daí o mestrado e doutorado em Ecologia e Recursos Naturais da UFSCar, foi o primeiro curso de ecologia no Brasil. (Pesquisador A, entrevista, 2015)

Destarte, o período inicial das pesquisas no Broa, conforme relatado pelo pesquisador $\mathrm{A}$, pa-

\footnotetext{
5 "Federal" refere-se à UFSCar, forma como a universidade é popularmente conhecida na cidade de São Carlos.

${ }^{6}$ A pesquisadora F é docente do Departamento de Ecologia e Biologia Evolutiva da UFSCar. Foi orientanda do pesquisador A e, a partir dos anos 2000, passou a orientar vários outros trabalhos sobre a Represa do Lobo.
} 
rece vir a responder três objetivos estratégicos da pesquisa nas ciências naturais da USP e UFSCar no início dos anos 1970:

a) O desenvolvimento da abordagem sistêmica e da ecologia. Dentro de um contexto internacional de preocupação ambiental e predomínio da ecologia como referencial científico para compreender os novos problemas ambientais, a pesquisa no Broa também visava posicionar institucionalmente a UFSCar na vanguarda desse novo campo disciplinar.

b) O aprofundamento dos estudos de reservatório. Tundisi (1977) aponta que, naquele período, não existiam pesquisas sobre ecossistemas lacustres no Brasil, e eram poucos os estudos desse tipo em regiões tropicais. A pesquisa no Broa, então, visava aprofundar as investigações nesse campo, tornando o Reservatório do Lobo um grande laboratório prático.

c) A capacitação de especialistas e pesquisadores nas áreas da ecologia e dos recursos hídricos, também como proposta de desenvolvimento institucional das universidades e consolidação da pós-graduação no país.

Dessa forma, é a partir desse projeto estratégico de desenvolvimento institucional e disciplinar que vem se formar um aparato de produção científica sobre a Represa do Lobo. Destacamos, nesse sentido, que o caráter estratégico do projeto, indicado por nosso entrevistado, deve-se à possibilidade de um melhor posicionamento das universidades e pesquisadores envolvidos no campo científico nacional. De acordo com Bourdieu (2008), a estrutura do campo é determinada pelas posições relacionais ocupadas pelos agentes sociais, de acordo com a posse de capitais específicos, sendo que o grupo dominante é aquele que ocupa determinada posição tal que a estrutura do campo atue em seu favor. Para o caso do Broa, isso significa que o projeto estratégico abre a possibilidade de posicionar os agentes envolvidos de forma privilegiada dentro da estrutura do campo, de modo que eles tenham acesso aos capitais e lucros simbólicos associados à posição dominante. Principalmente, o posicionamento estratégico no campo científico lhes dá poder sobre os critérios de classificação da realidade do campo, de forma que os referidos agentes possam orientar a produção desse campo segundo suas próprias visões.

Além disso, o projeto estratégico possibilita a construção do aparato de produção científica específica sobre o Broa, entendido como um conjunto de mecanismos que favorecem e facilitam a pesquisa e a produção de conhecimento nesse ambiente. Ainda, tal aparato é, simultaneamente, aquilo que permite o posicionamento privilegiado das universidades e pesquisadores envolvidos no campo científico, mas também é ele próprio reforçado pelas relações de poder estabelecidas dentro da estrutura do campo.

Nesse processo de posicionamento estratégico e construção do aparato de produção científica do Broa, algumas instituições tiveram participação fundamental: pela USP, o Centro de Recursos Hídricos e Ecologia Aplicada (CRHEA) e o Programa de Pós-Graduação em Ciências da Engenharia Ambiental (PPG-SEA); pela UFSCar, o Programa de Pós-Graduação em Ecologia e Recursos Naturais (PPG-ERN).

O PPG-ERN, criado em 1976, foi o primeiro curso de pós-graduação na área de ecologia no país. Atualmente, desenvolve pesquisas nas especialidades: ecologia de ecossistemas aquáticos, ecologia animal, ecologia vegetal, ecologia aplicada, gestão e planejamento ambiental, ecologia humana e etnoecologia e educação ambiental (PPG-ERN, s.d.). A 
despeito da ausência de instalações de campo nas proximidades da represa, esse programa participou da fundação do projeto estratégico de pesquisas no Broa e teve grande predomínio nos estudos no local durante a década de 1980.

Já o CRHEA é um complexo de laboratórios e instalações de campo, em área de 84 hectares, nas margens da Represa do Broa. Foi criado em 1976, com o objetivo de fomentar a pesquisa e o desenvolvimento na exploração e proteção dos recursos naturais. Hoje, é referência nacional para pesquisas em hidrobiologia, hidráulica e meteorologia (SHS, s.d.). O CRHEA está vinculado ao Departamento de Hidráulica e Saneamento e ao PPG-SEA. O PPG-SEA, criado em 1989, tornou-se a principal instituição a desenvolver pesquisas no reservatório, já a partir da década de 1990.

\section{A rede de pesquisadores do Broa}

Ademais, o caráter estratégico do projeto abordado na seção anterior - se reflete na formação dos pesquisadores envolvidos, pois se torna uma estratégia para alunos e jovens pesquisadores participarem das pesquisas na Represa do Lobo, como parte de sua trajetória de formação.

Como exemplo, as trajetórias da pesquisadora C e do pesquisador E simbolizam, de certo modo, a formação propiciada pelo aparato de produção científica do Broa, já na década de 1980.

Eu fiquei lá, eu trabalhei na represa [durante] o mestrado, dois anos e meio eu fiquei na represa. Depois eu fiz o doutorado, eu comparei a Represa do Broa com a Represa de Barra Bonita e sempre trabalhando em outros sistemas também. (Pesquisadora C, entrevista, 2015)
A pesquisadora $C$ é doutora em engenharia hidráulica e saneamento (1988) e livre docente em engenharia sanitária (1999), ambos pela USP. Foi orientanda do pesquisador A durante seu mestrado e doutorado. Posteriormente, como docente do Departamento de Hidráulica e Saneamento da USP, orientou novos trabalhos sobre a Represa do Broa.

Já o pesquisador E é doutor em ciências da engenharia ambiental (1994) e livre docente em ecologia (2002), ambos pela USP. Sua tese de livre docência faz um estudo comparativo dos reservatórios do Lobo e de Salto Grande (em Americana/ SP). Atualmente, é docente no Departamento de Hidráulica e Saneamento da USP.

O Broa entrou porque, quando eu cheguei [em São Carlos] em 1987, eu não estava no mestrado. Eu vim com aquela questão: "estou vindo do Mato Grosso do Sul, concorrendo com pessoas que são destaques em São Paulo, fazendo UFSCar, fazendo USP”. Então, o que eu fiz durante um ano foi estagiar em um laboratório, fazer algumas disciplinas que eu sabia que caiam na prova o conteúdo, e com isso eu acabei ficando no Broa. E a pessoa com a qual eu vim fazer o mestrado, com quem eu tive essa bolsa de aperfeiçoamento, era esposa do professor [Pesquisador A], que tinha seu laboratório dentro da Represa do Lobo. Ele era vinculado ao departamento ${ }^{7}$, a esposa dele, que era a [Pesquisadora B], era vinculada a UFSCar, e com isso eu ficava meio UFSCar/CRHEA. E pelo fato de eu não ter um número excessivo de disciplinas e ter uma flexibilidade maior de tempo, eu estava sempre presente em todas as pesquisas que estavam sendo feitas. Então, era meio curinga: "Ah, precisa ir para represa”, eu levantava a mão, "estou livre”. Primeiro pelo aprendizado e pelo fato de gostar. Então com isso eu acabei ficando no Broa muito mais tempo. E vendo a represa, e conhecendo a represa. E me interessando em fazer as pesquisas por lá. (Pesquisador E, entrevista, 2015)

\footnotetext{
${ }^{7}$ Em referência ao Departamento de Hidráulica e Saneamento (EESC/USP).
} 
Desde 2004, o pesquisador E orienta pesquisas sobre o Broa no PPG-SEA e na graduação em Engenharia Ambiental da USP, sendo o segundo principal orientador de pesquisas sobre o Broa em termos quantitativos. ${ }^{8}$ Nesse momento, a presença de um aparato já estruturado para produção científica sobre aquele ambiente funciona como uma importante facilidade para os pesquisadores ligados a essa estrutura, de forma a favorecer a reprodução e continuidade das pesquisas.

Quando eu entrei como professor, pelo fato do reservatório estar ali e eu estar começando a carreira, era muito mais fácil, em termos de custo. O reservatório estava do lado, não precisava ter grande investimento em termos de custo. O reservatório estava do lado, não precisava ter grande investimento em termos de pagamento de diárias, por aí afora. E nesse período começou a perceber que já alguns problemas despontavam. (Pesquisador E, entrevista, 2015)

$\mathrm{O}$ pesquisador $\mathrm{G}$, doutor em engenharia hidráulica e saneamento (2012) pela USP, foi orientado pela pesquisadora $\mathrm{C}$ em seu doutoramento. Hoje, docente do Departamento de Hidráulica e Saneamento da USP, também sinaliza as facilidades da pesquisa no Reservatório do Lobo, de forma semelhante ao pesquisador $\mathrm{E}$.

A minha orientadora, ela fez o mestrado e o doutorado dela no Broa. Não sei se você chegou a conversar com ela, porque você falou que chegou a conversar com outros professores aqui, ela é a [Pesquisadora C]. Ela foi minha orientadora do doutorado. E o Broa está muito próximo daqui de São Carlos. E o reservatório que foi escolhido para o [meu] doutorado ele não é longe, mas é mais longe do que o Broa, ele fica em Sorocaba. Então sempre fica aquela pulguinha atrás da orelha pensando: "nossa a gente está indo longe para avaliar um processo, para fazer um estudo ambiental, sendo que talvez aqui no nosso quintal a gente tem um problema". E aí meu primeiro projeto de pesquisa logo depois que eu entrei como professor aqui, eu inseri o Broa como um dos reservatórios a serem avaliados. Mantive esse reservatório do meu doutorado, coloquei o Broa e coloquei o reservatório de Barra Bonita também. Então esse meu projeto de pesquisa tem três reservatórios e um deles é o Broa. O interesse foi assim, que a gente vê o ritmo acelerado de degradação ambiental do reservatório e eu acho que como a gente está a 30 minutos do Broa é nossa obrigação produzir informações para tentar subsidiar uma recuperação daquele manancial. (Pesquisador G, entrevista, 2015)

Novamente, as facilidades da pesquisa já estruturada no Broa, somadas à percepção de que transformações ambientais ocorriam naquele ecossistema (em diferentes períodos), parecem ser as motivações da continuidade dos estudos na Represa do Lobo ao longo das décadas. Nesse sentido, é possível afirmar que, da mesma forma que a construção do aparato de produção científica do Broa foi uma estratégia para o posicionamento das universidades e pesquisadores no campo científico na década de 1970, hoje a participação nesse aparato continua sendo uma estratégia dos pesquisadores para melhor se posicionarem no campo científico.

Ademais, destacamos que a pesquisadora $\mathrm{C}$, o pesquisador $\mathrm{E}$ e o pesquisador $\mathrm{G}$ participaram do processo de formação de quadros científicos por meio da pesquisa no local, que resulta na formação de uma rede articulada de pesquisadores do Broa, ligados principalmente por relações de orientação. A Figura 1, a seguir, evidencia algumas das relações que se estabelecem entre os pesquisadores, no sentido da formação de redes. A ênfase dessa representação gráfica se coloca nas permanências dos pesquisadores ao longo das décadas e nas relações de orientação.

\footnotetext{
${ }^{8}$ Pesquisador E possui nove orientações concluídas sobre a Represa do Broa, além de sua própria tese de livre docência.
} 


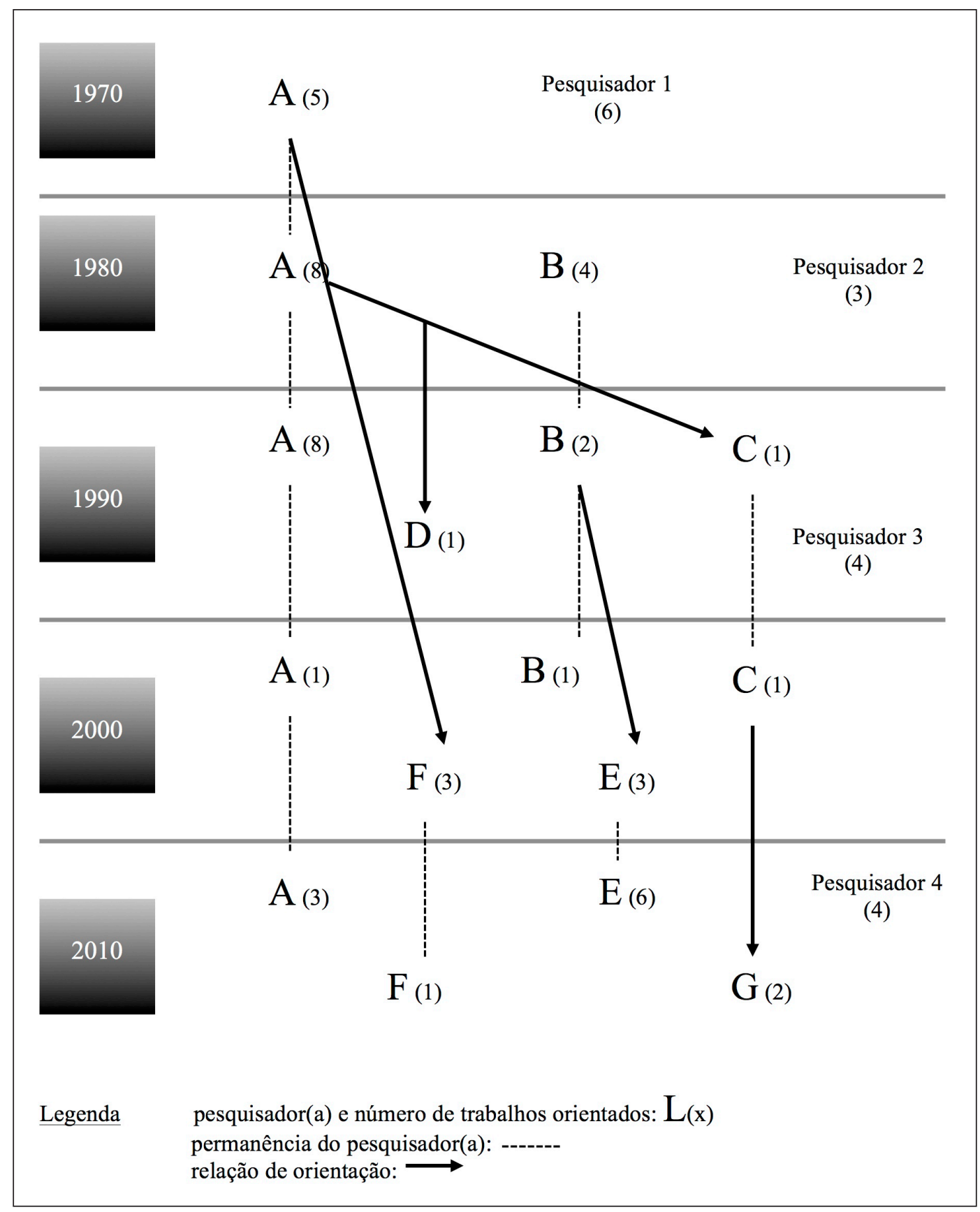

FIGURA 1 - Rede de pesquisadores do Broa, por década, 1972/2014.

FONTE: Plataforma Lattes e base de dados das bibliotecas da USP, UFSCar e UNESP. Elaborado pelos autores. 
Dessa forma, percebemos que três orientandas do pesquisador A (pesquisadoras C, D e F) tornaram-se docentes e passaram a orientar novos trabalhos sobre o reservatório. A pesquisadora $C$, particularmente, orientou o pesquisador $G$, que atualmente desenvolve pesquisa no local e possui duas orientações em andamento sobre a represa. Ainda, a pesquisadora B - esposa do pesquisador A e também pesquisadora na Represa do Broa orientou diversos trabalhos sobre o reservatório, incluindo o doutoramento do pesquisador E. O pesquisador $\mathrm{E}$, como mencionamos anteriormente, é um dos principais orientadores de trabalhos sobre o Broa na atualidade.

$\mathrm{O}$ grupo de pesquisadores ligados ao pesquisador $\mathrm{A}$, aqui representados pelos pesquisadores B, C, D, E, F e G, totaliza, portanto, 48 trabalhos orientados. O número representa $41 \%$ do total da produção científica sobre o Reservatório do Lobo. Os demais pesquisadores destacados no diagramapesquisadores 1, 2, 3 e 4 - foram responsáveis pela orientação de 17 trabalhos (15\% do total). ${ }^{9} \mathrm{O}$ grupo de cientistas articulado pelo pesquisador A é a única rede de pesquisa a atuar no espaço do Reservatório do Lobo, de forma que podemos perceber a posição dominante do pesquisador $\mathrm{A}$, e daqueles associados a ele, na estrutura das relações de produção científica sobre o Broa. A participação do pesquisador A na formação do PPG-ERN e PPG-SEA possibilitou não apenas o desenvolvimento de suas próprias pesquisas como principalmente a consolidação de uma rede de pesquisadores, capazes de manter a produção científica sobre o Broa e a estrutura de relações objetivas do campo científico. Ou seja, o próprio aparato de produção científica do Broa é controlado por esse grupo de pesquisadores articulados em rede, de forma a garantir tanto a reprodução do aparato como o posicionamento privilegiado de seus membros na estrutura do campo científico.

\section{As fases da pesquisa no Broa}

Também vale destacar que vários dos pesquisadores que mencionamos acima, especificamente a pesquisadora $\mathrm{C}$, o pesquisador $\mathrm{E}$ e o pesquisador $\mathrm{G}$, pertencem a um segundo momento institucional do aparato de produção científica do Broa, ligados principalmente ao CRHEA e ao PPG-SEA, da USP, e não mais ao PPG-ERN, da UFSCar. Como o pesquisador A pontua:

E a ideia do curso de Ciências da Engenharia Ambiental era fazer um programa mais voltado para a aplicação, porque aí, a partir da década de 1980, nós começamos a verificar o uso da represa para recreação, o aumento do uso da água, dos usos múltiplos da água, os impactos, foi feita uma estrada asfaltada que deu acesso. Ao dar acesso as pessoas começaram a construir casas e aumentou muito a população no entorno da represa, então o uso da represa e da bacia aumentaram bastante. Nós começamos a nos preocupar então com a gestão do processo. E hoje eu diria que está tudo canalizado para essa gestão. Todas as informações existentes estão muito dirigidas para a gestão. (Pesquisador A, entrevista, 2015)

Além dos perfis e das preocupações doPPG-ERN e do PPG-SEA serem diferentes, como aponta o pesquisador $\mathrm{A}$, podemos perceber que, ao longo das décadas de pesquisa na Represa do Lobo, os temas dos trabalhos sofreram significativa transformação. Se inicialmente eram quase exclusivamente volta-

\footnotetext{
${ }^{9}$ Os demais 51 trabalhos não mencionados (44\% do total) foram orientados por outros pesquisadores não articulados em rede. Tais pesquisadores orientaram apenas um ou dois trabalhos sobre o Reservatório do Lobo ao longo de suas carreiras, e seus alunos não orientaram novos trabalhos sobre o local depois de formados.
} 
dos às questões próprias da ecologia, da compreensão holística do ecossistema, as pesquisas mais recentes abordam uma maior variedade de temas a partir de perspectivas de outras disciplinas.

Alguns dos trabalhos defendidos sobre o Broa evidenciam essas mudanças. Na década de 1970, a principal pesquisa sobre o reservatório (Tundisi, 1977) reunia resultados iniciais de um diagnóstico e descrição do ecossistema da represa. Como veremos adiante, alguns pesquisadores referem-se a esse trabalho como o "Modelo Broa", pois ele descreve as funções ecológicas que mantêm a estabilidade do sistema. Tundisi (1977) realiza um estudo integrado do Reservatório do Lobo a partir da produção primária, "standing stock", fracionamento do fitoplancton e dos fatores ecológicos (climatologia e hidrologia) desse ecossistema. As conclusões de Tundisi (1977) apontam para a apresentação do ecossistema do Broa como um modelo ideal para regiões tropicais: como um ecossistema relativamente bem iluminado, pouco profundo, com grande instabilidade térmica e podendo apresentar alta taxa de produção primária, a depender da limitação por nitratos e fosfatos. Também conclui que o ambiente ainda não é poluído, o que permite sua manutenção como modelo de estudos para cadeias alimentares ainda não afetadas pela poluição.

Podemos notar, primeiramente, que a pesquisa realizada por Tundisi (1977) tem um caráter disciplinar claramente demarcado no campo da ecologia. Ela representa e sintetiza várias das preocupações mais comuns nos trabalhos científicos sobre o reservatório nas décadas de 1970 e 1980 . Em segundo lugar, a tese de Tundisi traz como marca a ideia de que a Represa do Broa pode funcionar, no âmbito da pesquisa científica, como um modelo ideal de ecossistema lacustre, com o qual outros reservatórios serão comparados. Os estudos comparativos entre diferentes reservatórios de fato são realizados ostensivamente a partir de 1978, como abordaremos adiante neste texto.

Por outro lado, quando observamos as pesquisas que estão sendo realizadas atualmente na represa, verificamos - como sugere o pesquisador A - que os temas de estudo são mais voltados à aplicação prática dos conhecimentos e à gestão do meio ambiente. Selecionados dois trabalhos defendidos na década atual (Periotto, 2011; Lamon, 2014) que ilustram essa mudança de olhares da pesquisa científica, assim como mostram uma maior diversidade disciplinar e temática para tais pesquisas.

Periotto (2011), por exemplo, faz uma avaliação dos serviços ecossistêmicos do reservatório e das áreas alagadas do Rio Itaqueri e Ribeirão do Lobo. Essa análise é pautada no referencial teórico da economia ecológica e visa estimar valores qualitativos e quantitativos dos serviços do ecossistema. A autora identifica e quantifica 20 serviços ecossistêmicos da Represa do Broa e das áreas alagadas, concluindo com a estimativa dos valores na ordem de US\$ 45.623,35 por hectare ao ano.

Em outro estudo, Lamon (2014) propõe uma metodologia para monitoramento de reservatórios, lagos e rios, a partir do desenvolvimento de microssensores para medição de oxigênio dissolvido, potencial de oxirredução e temperatura, além do desenvolvimento do software para o tratamento, leitura e registro dos dados coletados pelos microssensores. Os microssensores e software desenvolvidos pelo pesquisador foram testados por meio do monitoramento da Represa do Broa e associados a análises físico-químicas complementares para avaliação do nível trófico do reservatório.

Destarte, esses dois trabalhos mais recentes sobre a Represa do Broa foram selecionados por nós porque exemplificam a variedade de temas e enfoques que a pesquisa científica no reservatório tem tomado. Periotto (2011) apresenta uma análise 
firmemente assentada nos pressupostos da economia ecológica; já Lamon (2014) desenvolve novas tecnologias para o monitoramento da qualidade ambiental a partir do estudo do Reservatório do Lobo. Assim, economia, gestão ambiental e tecnologia são alguns dos temas que se somam aos estudos mais típicos da ecologia, nos últimos anos, para ampliar o leque de pesquisas sobre o Broa.

Não obstante tal ampliação, podemos perceber, nesse ponto, uma característica significativa da produção científica no Broa, qual seja, sua hierarquia disciplinar. As pesquisas no Broa estão marcadamente circunscritas ao domínio das ciências naturais, como fica evidente nos escopos de atuação do PPG-ERN e PPG-SEA, apresentados anteriormente. Também, as pesquisas ficam centradas no enquadramento da realidade física da represa e em suas possibilidades de gestão, como demonstram as pesquisas mais recentes.

Ainda sobre a variedade de temas estudados, o pesquisador A aponta que a pesquisa científica na Represa do Broa teve quatro fases. A fase inicial seria de diagnóstico do reservatório, para conhecê-lo e descrevê-lo. A segunda fase foi a etapa de comparação do Broa com outros reservatórios no estado e no país. A terceira fase, em parte concomitante com a segunda, seria de interpretação desses dados iniciais e aprofundamento das questões de pesquisa. A quarta fase, mais recente, refere-se à aplicação do conhecimento produzido sobre o Broa para resolução dos problemas práticos, mais ligados à gestão do espaço.

A primeira fase, de diagnóstico, foi marcada principalmente pela estruturação da pesquisa no local, pela construção do aparato de pesquisa e pela consolidação da abordagem sistêmica:

A primeira etapa foi o diagnóstico, não se conhecia nada. Então, essa primeira etapa foi montar um projeto que pudesse diagnosticar como funcionava o sistema, veio daí as ideias e o projeto sobre a interação entre climatologia, hidrologia, limnologia, biologia aquática. Diagnóstico. Esse diagnóstico durou de 1971 até 1980, durou quase dez anos, porque precisávamos montar os laboratórios, treinar as pessoas, as pessoas começaram a entender melhor porque nem todo mundo estava preparado para ter essa visão sistêmica e eu tive alguns embates, por exemplo, porque os botânicos queriam fazer pesquisa em Botânica no cerrado, mas eles não estavam nem aí para a represa. Não estavam pensando na represa. E eu dizia "não, mas tem uma interação, vocês têm que pensar na bacia hidrográfica". Então, o cerrado tem importância sim, mas não só do ponto de vista botânico, por causa da qualidade da água, da mata galeria, e interfere na qualidade da água. Então houve durante esse diagnóstico uma série de discussões para poder ensinar, instalar essa visão sistêmica do projeto. (Pesquisador A, entrevista, 2015)

A fase de comparação entre o Reservatório do Broa e outros ecossistemas lacustres teve início com uma proposta de tipologia de represas no Estado de São Paulo. Posteriormente, a partir do diagnóstico inicial e dos dados gerados por essa tipologia, emergiu uma metodologia de trabalho bastante difundida nas pesquisas do PPG-ERN e PPG-SEA: a comparação do "Modelo Broa" com outros reservatórios no país. Sobre a tipologia das represas em São Paulo, o pesquisador A relata:

Em 1978, eu estava fazendo muitos projetos para FAPESP, eu tive que fazer para poder montar os laboratórios, e isso chamou a atenção da FAPESP. Então, a FAPESP me chamou. Naquele tempo, a FAPESP tinha um projeto que chamava-se "Iniciativa". Esse projeto era uma espécie de sonho de todo pesquisador. E a FAPESP teve quatro "Iniciativas" na história dela e uma delas foi minha. Então, ela chamava o pesquisador e dizia: "Olha, nós identificamos você como uma liderança nesta área, faça um projeto que o dinheiro já está no banco. Não precisa submeter, você já foi avaliado”. Então, fizeram isso comigo, eu fui lá e isso 
foi em 1978, fui chamado pela diretoria científica da FAPESP, levamos um susto danado porque eu não sabia o que se tratava. Fui lá e me disseram "Olha, nós temos acompanhado o seu trabalho na Represa do Broa e nós estamos percebendo que você está fazendo um trabalho metodológico, tecnológico, está formando gente. E nós discutimos no conselho superior da FAPESP e a FAPESP decidiu montar, apoiar um grupo de ecologia no estado de São Paulo e escolhemos você. Então nós queremos que você traga duas páginas com a ideia principal porque o projeto já está concedido para você. Tem 7.100 .000 cruzeiros no banco (uns 500.000 dólares mais ou menos). E você, então, faça duas páginas dizendo o que você quer fazer com esse dinheiro". Bom, eu tinha estado na Espanha, e na Espanha o meu amigo Ramón Margalef, um ecólogo muito conhecido, tinha feito um projeto que se chamava "Tipologia de Represas da Espanha". Em dois anos ele estudou 100 reservatórios na Espanha para fazer uma comparação espacial, usando a mesma metodologia em todos eles. Eu falei, eu vou fazer a tipologia dos reservatórios do estado de São Paulo. E aí eu fiz a proposta, eles aprovaram, já estava aprovado. Convidei dois grupos, o Departamento de Zoologia da USP e o Instituto de Pesca, que nós não tínhamos condição de fazer tudo sozinho aqui, e aí nós estudamos 50 reservatórios em dois anos. (Pesquisador A, entrevista, novembro/2015)

\section{A proposta de realizar pesquisas comparativas} entre o Reservatório do Lobo e outras represas continuou sendo realizada por anos depois do encerramento do projeto "Iniciativa", mencionado pelo pesquisador A, até a atualidade. Esse tipo de metodologia de pesquisa é comum entre os trabalhos defendidos sobre o Broa e levantados por nós. Sobre esse tipo de pesquisa e a elaboração do "Modelo Broa", o pesquisador E comenta, referindo-se à segunda metade da década de 1980:

Mas a gente sempre usava o Reservatório do Lobo como um reservatório modelo, que é um reservatório que ele não tinha grandes impactos da área externa, não tínhamos indústrias. Alguns problemas com o reservatório estavam começando a se manifestar, mas não era uma coisa tão acentuada. Então, tudo que a gente fazia era "vamos comparar com o Modelo Broa". Tem até um trabalho de 1977, alguma coisa assim, final da década de 1970, que era o Modelo Broa, onde ele apresentava todo o funcionamento da represa, como funcionava, quais eram as funções, que a gente falava que eram funções de força, ou seja, mecanismos que faziam com que aquele reservatório fosse mantido. (Pesquisador E, entrevista, 2015)

E como exemplo da persistência dessa metodologia até hoje, temos o atual projeto de pesquisa do pesquisador $\mathrm{G}$ na Represa do Broa:

Então, a nossa ideia é entender o porquê o processo de eutrofização artificial desses reservatórios tem se acelerado nos últimos anos e o que tem levado a proliferação destes organismos específicos que são as cianobactérias. [...] Nós escolhemos esses três reservatórios [Broa, Barra Bonita e Itupararanga] porque a gente esperava que o Broa fosse o que iria apresentar melhor condição, então ele seria meio que um referencial para a gente, porque até pouco tempo atrás ele estava razoável. Barra Bonita, por outro lado, é um reservatório já historicamente muito impactado e o Itupararanga, que é o outro reservatório, também está com uma qualidade [ruim]. Mas os resultados obtidos até o momento nos surpreenderam nesse sentido, em algumas coletas que a gente faz, em alguns períodos do ano, o Reservatório do Broa apresenta a pior qualidade entre os três. (Pesquisador G, entrevista, 2015)

Retomando a descrição do pesquisador A, a etapa seguinte dos trabalhos no Broa refere-se a um período de interpretação e aprofundamento dos dados iniciais. Esse esforço de pesquisa ocorre de forma concomitante com o desenvolvimento da metodologia comparativa apresentada acima. A interpretação dos dados visava, além da melhor compreensão do reservatório, ao estudo da região como um todo, enfocando principalmente a bacia hidrográfica. 
Então veio a interpretação. Como é que funciona a represa? Como é que ela responde ao clima? Quais são as relações entre temperatura do ar e a temperatura da água, a circulação, e como é que a comunidade biológica responde a isso. Essa foi a interpretação. Uma outra fase, que foi a terceira fase do processo, foi avançar mais nessa interpretação não só com relação à represa, mas à bacia hidrográfica. Quais as relações da bacia hidrográfica com a represa? O que a bacia contribui para a represa? Alargou um pouco a visão. (Pesquisador A, entrevista, 2015).

Finalmente, a quarta fase das pesquisas no reservatório, conforme apresentadas pelo pesquisador $\mathrm{A}$, diz respeito às pesquisas realizadas mais recentemente, a partir dos anos 2000. São trabalhos voltados para a aplicação dos conhecimentos na gestão do ambiente, particularmente pela perspectiva da valoração econômica dos recursos naturais e dos instrumentos legais de gestão pública do meio ambiente.

E a quarta fase foi a fase da aplicação, da aplicação do conhecimento para resolver problemas práticos. Foi a quarta fase do projeto que ainda se encontra em evolução. [...] Isso aconteceu agora, a partir dos anos 2000, mais ou menos quando fez uns 40 anos da pesquisa... Um pouco menos, 30 e poucos anos de pesquisa. Nós já tínhamos elementos para começar a aplicar [...] Então a última fase do processo que é essa valoração, a questão econômica, e a integração maior com a sociedade. E agora o corolário de tudo isso é formar o Parque Estadual. O Broa é um laboratório e a ideia inicial era essa mesmo, era fazer um laboratório. (Pesquisador A, entrevista, 2015)

O parque estadual que o pesquisador A menciona se refere à proposta de criação do Parque Estadual do Itaqueri-Lobo, elaborada pelo próprio pesquisador e encaminhada ao governo do Estado de São Paulo. O pesquisador A, inclusive, participou efetivamente da criação da Área de Proteção Ambiental de Corumbataí1 ${ }^{10}$, na década de 1980 , evidenciando a posição do pesquisador no campo político e seu poder de influência em determinadas decisões sobre a gestão ambiental do espaço próximo à Represa do Broa.

Nós iniciamos, já na década de 80 , uma outra movimentação que também funcionou bastante. Foi feita pelo Prof. Aziz Absaber, pelo Prof. Paulo Nogueira Neto e por mim. Nós fizemos uma proposta para o Governo do Estado para criar a APA de Corumbataí. A APA de Corumbataí é uma área de $1.000 \mathrm{~km}^{2}$ no centro do estado de São Paulo, que envolve a represa e a bacia hidrográfica. Mas ela é bem maior, porque a bacia hidrográfica do Itaqueri-Lobo tem $230 \mathrm{~km}^{2}$. A ideia era proteger as encostas de basalto, que são florestadas, lá tem árvore de boa qualidade e é um refúgio de biodiversidade. Levamos a ideia para o governador Montoro, na época, ele aprovou imediatamente e fizemos o projeto. Então, criou-se a primeira APA de Corumbataí, que é uma área de preservação: preservação das matas galeria, enfim das estruturas ecológicas naturais da região. [...] O movimento nosso agora é fazer o Parque Estadual do Itaqueri-Lobo, cuja finalidade principal é preservar a bacia hidrográfica. E como Parque Estadual. Já mandei para o Ministério Público, mandei para a Secretaria do Meio Ambiente, estão estudando essa possibilidade. E é uma inovação interessante, porque você protege mesmo toda a região. (Pesquisador A, entrevista, 2015)

Além disso, a Represa do Broa e a Bacia Hidrográfica do Itaqueri-Lobo são atualmente um dos 30 sítios do Programa de Pesquisas Ecológicas de Longa Duração (PELD), financiado pelo CNPq. O PELD foi criado pelo próprio pesquisador A quando presidente do $\mathrm{CNPq}$, como uma rede de locais

\footnotetext{
${ }^{10}$ A Represa do Broa encontra-se dentro da Área de Proteção Ambiental Corumbataí-Tejupá-Botucatu, especificamente no perímetro Corumbataí, criada em 1983 pelo Decreto Estadual nº 20.960.
} 
de referência para a pesquisa científica no tema da ecologia de ecossistemas (CNPq, s.d.). A proposta desse programa é a geração de conhecimento qualificado sobre os ecossistemas nacionais e sua biodiversidade, por meio de longas séries temporais de dados. O Broa foi incluído no PELD apenas em 2009, sob coordenação do pesquisador A e vínculo institucional com o IIE.

Por outro lado, o que aconteceu também nos últimos anos foi que o trabalho nosso na bacia hidrográfica foi reconhecido pelo CNPq e pela FAPESP: hoje eles são parte do PELD. O que é o PELD? É um projeto que eu comecei quando eu era presidente do CNPq, eu comecei o projeto com a seguinte finalidade e perspectiva: nós precisamos medir o funcionamento dos sistemas ecológicos no Brasil, em todas as latitudes, em todos os diferentes biomas. Para isso temos que montar projetos de longa duração. Isso foi inspirado em um projeto que tem nos Estados Unidos que é o LTER (Long Term Ecological Research), em que eles tem lá uma série de sites onde eles pesquisam por muito tempo, 200 anos. O projeto é para ser em 200 anos, evidentemente não os mesmos pesquisadores, vai mudando, mas vai continuando. Eu falei: "bom, vamos fazer isso". Aí fundamos o PELD com 11 sites. Como eu era presidente do CNPq, mas coordenava o projeto aqui [no Broa], eu não podia apresentar o projeto [do Broa para o PELD]. Só depois que eu saí [da presidência do CNPq] é que o projeto nosso aqui entrou como parte do PELD, que recebe então financiamentos regulares da FAPESP e do CNPq para desenvolver os projetos de longo termo, de longa duração. (Pesquisador A, entrevista, 2015)

A criação do PELD e a posterior adesão do Broa ilustram as relações indissociáveis entre discurso e poder na produção científica. A visão do pesquisador A, expressa no discurso da necessidade de medição do funcionamento dos sistemas ecológicos do país, se apoia e opera um suporte institucional por meio das agências de fomento à pesquisa científica. Por um lado, como afirma
Foucault (2013), o discurso classificado como verdade está circularmente ligado a sistemas de poder que o produzem e o apoiam. Por outro, a posição privilegiada do pesquisador A no campo científico confere a ele certo poder sobre os critérios de classificação da realidade, de forma a orientar a produção desse campo segundo suas próprias visões. Desse modo, a necessidade de estudos ecológicos de longa duração é legitimada pela posição do pesquisador no campo, ao passo que é efetivamente produzida pelo suporte institucional quando se torna um programa de pesquisa nacionalmente financiado. A partir disso, discurso e suporte institucional se reforçam mutuamente, produzindo os efeitos de poder específicos do regime de verdade: nesse caso, reorientando um campo de pesquisas e de produção de conhecimentos sobre o meio ambiente.

\section{Conclusões}

Com base no conceito de campo científico, verificamos como se constituiu um aparato de produção científica sobre a Represa do Broa, assim como uma estrutura de relações hierárquicas entre os agentes que participam dessa produção. Vale destacar que a pesquisa no Broa surgiu como um programa estratégico de desenvolvimento institucional (USP e UFSCar) e disciplinar (ecologia). A escolha desse ambiente como objeto de estudo ou local para o desenvolvimento de pesquisas segue funcionando hoje como opção estratégica dos cientistas para sua inserção e posicionamento no campo científico.

Ademais, é importante ressaltar que tanto a produção científica sobre a Represa do Broa quanto os relatos colhidos por meio de nossas entrevistas são discursos sobre aquele ambiente, construídos a partir da interação do habitus com o espaço social. 
Isso significa dizer que os discursos expressam uma visão de mundo a partir da relação dinâmica e reflexiva entre as experiências individuais dos agentes sociais e as estruturas objetivas de classificação do mundo social. Nesse sentido, podemos notar que a produção sistemática de discursos sobre o reservatório, suportados pelo estatuto da ciência, segue a hierarquia disciplinar do campo científico: verificamos a dominância das ciências naturais e engenharias - evidenciada pelo posicionamento dos Programas de Pós-Graduação em Ecologia e Recursos Naturais e em Ciências da Engenharia Ambiental. Também, são discursos centrados na realidade física da represa e nas suas possibilidades de gestão, como fica ainda mais aparente nas pesquisas recentes.

Entre esses discursos, ocorre ainda o predomínio de um grupo especificamente situado e articulado na estrutura das relações de produção científica sobre o Broa, qual seja, a rede de pesquisadores ligados ao pesquisador A. Nossas entrevistas confirmam a posição dominante do pesquisador $\mathrm{A}$ e seu grupo (no PPG-ERN e PPG-SEA) no campo científico, principalmente por meio dos grandes

\section{Referências}

Beck, U. Sociedade de Risco: rumo a uma outra modernidade. 2 ed. São Paulo: Editora 34, 2011.

Bourdieu, P. Os usos sociais da Ciência: por uma Sociologia clínica do campo científico. São Paulo: Editora Unesp, 2004.

Bourdieu, P. Para uma Sociologia da Ciência. Lisboa: Edições 70, 2008.

Campregher, R. Tantas verdades: estudo sociológico dos discursos científicos sobre a Represa do Lobo/Broa. São Carlos, Dissertação (Mestrado em Sociologia) - UFSCar, financiamentos de pesquisa recebidos por eles (como o Projeto "Iniciativa" da FAPESP e o PELD do CNPq). Podemos concluir, inclusive, que a boa relação do grupo com as agências de fomento à pesquisa foi fator importante para a estruturação do aparato de pesquisa no Broa. Não menos importante é o posicionamento destacado do pesquisador A no campo político, como pudemos perceber por meio de sua atuação na criação da APA de Corumbataí e na proposta de criação do Parque Estadual do Itaqueri-Lobo.

Em síntese, o caso da Represa do Lobo demonstra de forma ilustrativa a transformação da natureza em objeto de pesquisa, bem como o processo de produção de conhecimento científico sobre o meio ambiente.

\section{Agradecimentos}

Agradecemos os suportes da Fundação de Amparo à Pesquisa do Estado de São Paulo (FAPESP) e do Conselho Nacional de Desenvolvimento Científico e Tecnológico (CNPq).

2016. Disponível em: <https://repositorio.ufscar.br/handle/ ufscar/7145>

$\mathrm{CNPq}$ - Conselho Nacional de Desenvolvimento Científico e Tecnológico. PELD - Programa de Pesquisas Ecológicas de Longa Duração, s.d. Disponível em: $<$ http://www.cnpq. br/web/guest/apresentacao7>. Acesso em: dez. 2015.

Foucault, M. Microfísica do poder. 26. ed. São Paulo: Graal, 2013.

Giddens, A. A política da mudança climática. Rio de Janeiro: Zahar, 2010. 
Hannigan, J. Sociologia ambiental. Petrópolis: Vozes, 2009.

IIE - Instituto Internacional de Ecologia. Quem somos, s.d. Disponível em: <http://www.iie.com.br/index.php/sobre/ quem-somos>. Acesso em: maio 2015.

Iucif, N. G. Estudos na Represa do Lobo (Itirapina/Brotas - SP): revisão de algumas teses e dissertações produzidas pelo PPG-SEA. São Carlos, Monografia (Graduação em Engenharia Ambiental) - USP, 2011. Disponível em: $<$ http://www.tcc.sc.usp.br/tce/disponiveis/18/180300/ tce-29032012-102513/?\&lang=br>.

Lamon, A. W. Aplicação de microssensores no monitoramento de oxigênio dissolvido, potencial redox e temperatura em estudos limnológicos. São Carlos, Dissertação (Mestrado em Ciências da Engenharia Ambiental) - USP, 2014. Disponível em: $<$ http://www.teses.usp.br/teses/disponiveis/18/18139/tde-10102014-131806/pt-br.php>.

Martínez Alier, J. O ecologismo dos pobres: conflitos ambientais e linguagens de valoração. 2. ed. São Paulo: Contexto, 2012.

Periotto, N. A. Serviços ecossistêmicos do reservatório da UHE Carlos Botelho (Lobo-Broa): uma nova abordagem para o gerenciamento e planejamento dos múltiplos usos de represas. São Carlos, Dissertação (Mestrado em Ecologia e Recursos Naturais) - UFSCar, 2011. Disponível em: $<$ https://repositorio.ufscar.br/handle/ufscar/2042?show=full $>$.

PPG-ERN - Programa de Pós-Graduação em Ecologia e Recursos Naturais/UFSCar. História da criação e funcionamento do programa, s.d. Disponível em <http://www. ppgern.ufscar.br/apresentacao $>$. Acesso em: maio 2015.

Queiroz, O. T. M. M. Impactos das atividades turísticas em área de reservatório: uma avaliação sócio-ambiental do uso e ocupação na área da Represa do Lobo, município de Itirapina, SP. São Carlos, Tese (Doutorado em Ciências da Engenharia Ambiental) - USP, 2000.

SHS - Departamento de Hidráulica e Saneamento/EESCUSP. Departamento de Hidráulica e Saneamento, s.d. Disponível em $<$ http://www.shs.eesc.usp.br/administracao/ historico/>. Acesso em: maio 2015.

Tundisi, J. G. Produção primaria, "standing stock”, fracionamento do fitoplancton e fatores ecológicos em ecossistema lacustre artificial (Represa do Broa, São Carlos). Ribeirão Preto, Tese (Livre docência) - USP, 1977. 